\title{
Clinical characteristics and long-term response to mood stabilizers in patients with bipolar disorder and different age at onset
}

This article was published in the following Dove Press journal:

Neuropsychiatric Disease and Treatment

14 July 2009

Number of times this article has been viewed

\author{
Bernardo Dell'Osso' \\ Massimiliano Buoli' \\ Riccardo Riundi² \\ Nazario D'Urso' \\ Sara Pozzoli' \\ Roberta Bassetti ${ }^{2}$ \\ Emanuela Mundo' \\ A Carlo Altamura' \\ 'Department of Psychiatry, University \\ of Milan, Fondazione IRCCS Ospedale \\ Maggiore Policlinico, Mangiagalli e \\ Regina Elena, Milano, Italy; ${ }^{2}$ Department \\ of Clinical Sciences, Luigi Sacco, \\ Milano, Italy
}

Correspondence: Bernardo Dell'Osso Department of Psychiatry, University of Milan, Fondazione IRCCS Ospedale Maggiore Policlinico, Via F Sforza 35 , 20I22, Milan, Italy

Tel +39025503 5994

Fax +390250320310

Email bernardo.dellosso@policlinico.mi.it
Introduction: Bipolar disorder (BD) is a prevalent, comorbid, and impairing condition. Potential predictors of response to pharmacological treatment are object of continuous investigation in patients with BD. The present naturalistic study was aimed to assess clinical features and longterm response to mood stabilizers in a sample of bipolar subjects with different ages at onset. Methods: The study sample included 108 euthymic patients, diagnosed as affected by BD, either type I or II, according to the DSM-IV-TR, who were started on mood stabilizer treatment. Patients were followed-up for 24 months and the occurrence of any mood episode collected. At the end of the follow-up, patients were divided in 3 subgroups according to the age at onset (early-onset $\leq 30$ years, middle-onset $>30-\leq 45$ years, and late-onset $>45$ years, respectively) and the long-term response to mood stabilizers was compared between them along with other clinical features.

Results: The three subgroups showed significant differences in terms of clinical and demographic features and, with respect to long-term response to mood stabilizers, the early-onset subgroup showed a better outcome in terms of reduction of major depressive episodes during the 24-month follow-up compared to the other subgroups (one way ANOVA, $F=3.57, \mathrm{p}=0.032$ ).

Conclusions: Even though further controlled studies are needed to clarify the relationship between age at onset and outcome in $\mathrm{BD}$, the present follow-up study suggests clinical peculiarities and different patterns of response to mood stabilizers across distinct subgroups of patients with BD and different ages at onset.

Keywords: bipolar disorder, age at onset (AAO), mood stabilizers, long-term treatment

\section{Introduction}

Bipolar disorder (BD) is a chronic and impairing mental disorder with estimated lifetime prevalence of around $2.0 \%$ in general population. ${ }^{1,2}$ Pharmacological treatment of bipolar patients is often complex and aimed to symptoms remission and, ultimately, to the prevention of recurrences. Over the last two decades, researchers have focused their efforts in identifying clinical predictors of treatment response and long-term outcome in BD. The aim of the present study was to investigate the long-term response to mood stabilizers and to examine the associations between other clinical/demographic characteristics in a sample of bipolar patients divided into three subgroups according to their ages at onset (AAO).

With regard to potential predictors of treatment response in $\mathrm{BD}$, many variables have been investigated. The presence of rapid-cycling course, for example, has been associated with worse treatment-response, poorer long-term prognosis, and higher suicide risk. ${ }^{3-5}$ 
The role of the duration of untreated illness (DUI) as predictor of outcome and long-term course in BD is controversial with studies indicating a negative influence in relation to outcome for longer treatment delay in initiating mood stabilizer therapy ${ }^{6}$ and other investigation reporting no differences in the final outcome of long-term treatments, lithium in particular. ${ }^{7-10}$

Studies investigating the prognostic role of gender in BD have shown mixed results. An extensive review assessing gender differences in terms of presentation and course in $\mathrm{BD}$ indicated that there was no evidence of gender influence on treatment response to mood stabilizers. ${ }^{11}$ A previous retrospective three-year study conducted with 131 bipolar patients showed that AAO and number of affective episodes of any polarity did not differ across genders. ${ }^{12} \mathrm{~A}$ more recent retrospective study conducted with 211 bipolar patients concluded that men and women were different in terms of episode polarity at onset as well as comorbidity patterns, with men reporting more frequently mania at the onset of bipolar I disorder and also showing higher rates of comorbid alcohol and cannabis abuse/dependence. ${ }^{13}$

With regard to the relationship between $\mathrm{AAO}$ and severity of clinical features in $\mathrm{BD}$, a recent study reported that early AAO was associated with more severe clinical features but delayed treatment-seeking. ${ }^{14}$ A previous large retrospective study reported that early (13-18 years) and very early onset ( $<13$ years) bipolar patients showed higher rates of comorbid anxiety disorders and substance abuse, more recurrences, shorter periods of euthymia as well as more suicide attempts and violent behaviors. ${ }^{15}$ Furthermore, recent reports suggest that late onset BD would be more frequently associated with organic brain diseases, ${ }^{16}$ supporting the hypothesis that late onset BD may share some symptom domains with the early onset subtype, but have potential different etiology. Nevertheless, there is no uniform consensus in defining specific thresholds in relation to AAO. On one hand, a recent study investigating cognitive impairment in elderly bipolar patients defined the onset of BD prior to the age of 40 years as early-onset. ${ }^{17}$ Another recent study identifying factors contributing to relapse and hospitalization in elderly bipolar patients established an AAO cut-off between early and late onset $\mathrm{BD}$ at age $45 .{ }^{18}$ On the other hand, threshold values for early onset in $\mathrm{BD}$ have been repeatedly indicated prior to the age of 18 years ${ }^{15}$ and it is not clear how to consider BD patients between 30 and 40 years with respect to AAO. As a matter of fact, Leboyer and colleagues supported the existence of three bipolar subgroups based on AAO: early $(17.4 \pm 2.3$ years $)$, intermediate $(25.1 \pm 6.2$ years $)$, and late-onset $(40.4 \pm 11.3 \text { years })^{19}$ following previous investigation in the field. ${ }^{20,21}$ The authors, however, concluded that accurate AAO thresholds to define valid subgroups of patients with BD are still an object of debate.

In order to investigate the relationship between long-term response to mood stabilizers and AAO in a sample of bipolar patients we conducted the present naturalistic study that explored this relationship not only in early- and late-onset patients but also in intermediate-onset bipolar subjects. In addition, associations between other clinical/demographic characteristics and long-term response in these sub-groups of patients were investigated.

\section{Subjects and methods \\ Subjects}

The study sample included initially 137 consecutive euthymic drug-free patients (63 males and 74 females) diagnosed as affected by BD, either type I or II, according to the Diagnostic and Statistical Manual for Mental Disorders, 4th edition, text-revision criteria (DSM-IV-TR). ${ }^{22}$ Euthymia was defined as the absence of any major mood episode (depressive, manic/ hypomanic, or mixed) for at least two months.

Diagnoses were made through the administration of a semi-structured clinical interview for DSM-Axis I Disorders (SCID). ${ }^{23}$ Before starting the pharmacological treatment with mood stabilizers and entering the 24-month follow-up, the following demographic (gender and age) and clinical variables (family history for mood disorders, age at onset, polarity of the first episode, type of $\mathrm{BD}$, age at the first pharmacological treatment, duration of untreated illness (DUI), duration of illness, comorbidity with other psychiatric disorders, and presence of rapid cycling course) were collected.

Exclusion criteria included comorbid organic disorders, mental retardation, personality disorders severe enough to interfere with study participation (assessed through the SCID II), and lack of compliance. If a comorbid disorder was present, BD had to be the primary disorder, ie, it caused the most significant distress and dysfunction and provided the primary motivation to seek treatment.

All patients were assessed, interviewed, treated and followed-up at the Mood Disorders Outpatient Clinic within the University Department of Psychiatry of Milan and had given written informed consent to participate into the study after receiving a full explanation of the study protocol.

\section{Methods}

After the baseline visit, patients were started on mood-stabilizer treatment, entering a 24-month follow-up with monthly 
control visits. Mood-stabilizer treatment included the following psychotropic compounds: Lithium, anticonvulsants (ie, valproate and carbamazepine) and atypical antipsychotics (ie, quetiapine, olanzapine, and risperidone). These compounds were chosen by treating psychiatrists on the basis of their clinical evaluations. Each compound had to be administered at standard dosages according to currently available guidelines, ${ }^{24}$ and within therapeutic plasma levels for lithium and valproate $(0.5-1.5 \mathrm{mEq} / 1$ and $50-150 \mu \mathrm{g} / \mathrm{ml}$, respectively). Concomitant pharmacological treatment with benzodiazepines as prohypnotic agents was allowed whereas antidepressant treatment, when present, had to be maintained at fixed dosages for all the duration of the follow-up.

The occurrence of any mood episode during the follow-up period represented the main outcome measure for assessing long-term response. In fact, from the beginning of the study and throughout the 24-month follow-up period, patients were assessed monthly by trained psychiatrists who administered the 21-item Hamilton Depression Rating Scale (HAMD-21) ${ }^{25}$ and the Young Mania Rating Scale (YMRS) ${ }^{26}$ in order to identify or to exclude the recurrence of any major mood episode. Depressive recurrences were diagnosed through the SCID and on the basis of a HAMD-21 total score $>18$ for at least two weeks. Manic and hypomanic recurrences were diagnosed through the SCID and on the basis of a YMRS total score $\geq 20$ or YMRS total score $\geq 10$ and $<20$ for at least one week, respectively. Mixed recurrences were diagnosed through the SCID and with a HAMD-21 total score $>18$ and YMRS total score $\geq 20$ for at least one week. Patients were considered euthymic if their HAMD-21 total score was $<8$ and their YMRS total score was $<10$.

For the purpose of the study, at the end of follow-up, patients were divided into three subgroups according to the AAO: an early onset subgroup (age at onset $\leq 30$ years); a middle onset subgroup (age at onset $>30-\leq 45$ years); and a late onset subgroup (age at onset $>45$ years). Such a division was performed taking into account previous investigation in the field. ${ }^{19-21}$ AAO was collected during the clinical interview (SCID) by trained psychiatrists (BD, MB, RR, SP, RB) with established inter-rater reliability and controlled with available relatives. In addition, a further control with previous medical/psychiatric records was performed for the majority of patients.

Descriptive analyses of demographic and clinical variables were performed on the total sample and on the three subgroups. Long-term response to mood stabilizer treatment was compared between the three subgroups of patients using one way analysis of variances (ANOVAs), whereas dichotomous clinical variables were analyzed with chi-square tests. For all the analyses, the level of statistical significance was set at 0.05 . All the statistical analyses were performed using the SPSS for Windows software (version 15.0; SPSS Inc., Chicago, IL).

\section{Results}

One hundred and eight patients (43 males and 65 females) completed the 24-month follow-up. Clinical and demographic features of the study sample are reported in Table 1. Twenty-nine patients (20 males and nine females) did not complete the follow-up for different reasons (nine subjects missed two consecutive visits and were excluded from the study, nine subjects withdrew from the study due to side effects, six patients needed a major change in the pharmacological regimen, eg, the augmentation of an antidepressant or a second mood stabilizer, and five subjects were not compliant to the prescribed therapy) and were not included in the final analysis. Nevertheless, drop-outs were homogeneous across the three subgroups of patients.

Mean AAOs were respectively 23.39 years $( \pm 4.78)$ in the early-onset subgroup, 37.13 years $( \pm 4.15)$ in the middle onset subgroup, and 53.42 years $( \pm 5.79)$ in the late-onset subgroup.

In terms of clinical and demographic characteristics, the three subgroups were different with respect to the type of mood stabilizer prescribed, with a prevalence of atypical antipsychotics in the late-onset subgroup and lithium/ valproate in the early-onset subgroup $\left(\chi^{2}=34.74\right.$, df $=14$; $\mathrm{p}=0.001)$. The duration of illness was significantly higher in the early-onset subgroup compared to the late-onset subgroup ( $\mathrm{F}=8.43 ; \mathrm{p}<0.0001$; Bonferroni, $\mathrm{p}<0.0001)$ as well as the DUI $(F=3.59 ; p=0.031$; Bonferroni, $p=0.026)$. The age at the first pharmacological treatment was higher in the late-onset subgroup compared to the other subgroups $(\mathrm{F}=102.10 ; \mathrm{p}<0.0001 ;$ Bonferroni, $\mathrm{p}<0.0001)$. Baseline comorbidity with other psychiatric disorders showed a higher prevalence of substance abuse in the early-onset subgroup compared to the other subgroups $\left(\chi^{2}=28.28\right.$, $\mathrm{df}=16 ; \mathrm{p}=0.022)$. There were no differences with respect to gender $\left(\chi^{2}=1.58, \mathrm{df}=2 ; \mathrm{p}=0.516\right)$, diagnostic subtype $\left(\chi^{2}=0.09, \mathrm{df}=2 ; \mathrm{p}=0.967\right)$, development of rapid cycling course $\left(\chi^{2}=0.72, \mathrm{df}=2 ; \mathrm{p}=0.771\right)$, type of the first episode $\left(\chi^{2}=3.49, \mathrm{df}=2 ; \mathrm{p}=0.17\right)$, and family history for psychiatric disorders $\left(\chi^{2}=2.71, \mathrm{df}=6 ; \mathrm{p}=0.87\right)$.

With respect to long-term response, mood stabilizers showed to be more effective in preventing major depressive episodes in the early-onset subgroup compared to the other subgroups $(\mathrm{F}=3.57, \mathrm{p}=0.032$; Bonferroni, $\mathrm{p}=0.014)$. 
Table I Demographic and clinical features of the total sample and of the three subgroups divided according to the age at onset

\begin{tabular}{|c|c|c|c|c|c|}
\hline & \multirow[t]{2}{*}{$\mathbf{N}$} & \multirow{2}{*}{$\begin{array}{l}\text { Total sample } \\
108\end{array}$} & \multirow{2}{*}{$\begin{array}{l}\text { Early onset } \\
\text { 5I }\end{array}$} & \multirow{2}{*}{$\begin{array}{l}\text { Middle onset } \\
38\end{array}$} & \multirow{2}{*}{$\begin{array}{l}\text { Late onset } \\
19\end{array}$} \\
\hline & & & & & \\
\hline \multirow[t]{2}{*}{ Gender } & Male & $43(39.8)$ & $19(37.3)$ & $14(36.8)$ & $10(52.6)$ \\
\hline & Female & $65(60.2)$ & $32(62.7)$ & $24(63.2)$ & $9(47.4)$ \\
\hline \multirow[t]{2}{*}{ Diagnosis } & Bipolar I & $39(36.1)$ & $19(37.3)$ & $13(34.2)$ & $7(36.8)$ \\
\hline & Bipolar II & $69(63.9)$ & $32(62.7)$ & $25(65.8)$ & $12(63.2)$ \\
\hline \multirow[t]{2}{*}{ Type of first episode } & Depressive & $80(74.0)$ & $34(66.7)$ & $32(84.2)$ & 14 (73.7) \\
\hline & Manic/hypomanic & $28(26.0)$ & $17(33.3)$ & $6(15.8)$ & $5(26.3)$ \\
\hline \multirow[t]{4}{*}{ Family history } & None & $49(45.4)$ & $22(43.1)$ & $18(47.4)$ & $9(47.4)$ \\
\hline & Affective disorders & $48(44.4)$ & $23(45.1)$ & $17(44.7)$ & $8(42.0)$ \\
\hline & Schizophrenia & $4(3.7)$ & I (2.0) & $2(5.3)$ & I (5.3) \\
\hline & Anxiety disorders & $7(6.5)$ & $5(9.8)$ & I (2.6) & I (5.3) \\
\hline \multirow{8}{*}{$\begin{array}{l}\text { Comorbidity } \\
\text { (Lifetime) }\end{array}$} & None & $65(60.1)$ & $27(52.9)$ & $22(57.9)$ & $16(84.2)$ \\
\hline & Substance abuse & II (I0.2) & $10(19.6)$ & $0(0.0)$ & $\mathrm{I}(5.3)$ \\
\hline & Personality disorders & $2(1.9)$ & I (2.0) & I (2.6) & $0(0.0)$ \\
\hline & Panic disorder & $15(13.9)$ & 7 (13.7) & $7(18.4)$ & I (5.3) \\
\hline & General anxiety disorder & $5(4.6)$ & I (2.0) & $4(10.5)$ & $0(0.0)$ \\
\hline & Obsessive-compulsive disorder & $4(3.7)$ & $4(7.8)$ & $0(0.0)$ & $0(0.0)$ \\
\hline & Eating disorders & $3(2.8)$ & I (2.0) & $2(5.3)$ & $0(0.0)$ \\
\hline & Somatoform disorders & $3(2.8)$ & $0(0.0)$ & $2(5.3)$ & I (5.3) \\
\hline \multirow[t]{2}{*}{ Rapid cycling } & Yes & $16(14.8)$ & $7(13.7)$ & $7(18.4)$ & $2(14.8)$ \\
\hline & No & $92(85.2)$ & $44(86.3)$ & $3 I(8 I .6)$ & $17(85.2)$ \\
\hline \multicolumn{6}{|l|}{ Mood stabilizers $\infty$} \\
\hline & Atypical antipsychotics & $20(18.5)$ & $4(7.8)$ & $7(18.4)$ & $9(47.4)$ \\
\hline & Lithium & $43(39.8)$ & $28(54.9)$ & $12(31.6)$ & $3(15.8)$ \\
\hline & Anticonvulsants & $45(4 I .7)$ & $19(37.3)$ & $19(50.0)$ & $7(36.8)$ \\
\hline Age* & & $51.06( \pm 12.59)$ & $44.47( \pm 12.01)$ & $53.32( \pm 9.37)$ & $64.26( \pm 6.61)$ \\
\hline \multicolumn{2}{|c|}{ Age of the first pharmacological treatment ${ }^{* *}$} & $36.83( \pm 11.93)$ & $28.08( \pm 8.19)$ & $39.84( \pm 5.69)$ & $54.32( \pm 5.85)$ \\
\hline \multicolumn{2}{|c|}{ Duration of untreated illness (DUI) ${ }^{\circ}$ years } & $10.04( \pm 9.79)$ & II.88 ( \pm I I.04) & $10.08( \pm 9.03)$ & $5.00( \pm 5.25)$ \\
\hline \multicolumn{2}{|c|}{ Duration of illness ${ }^{\square}$ years } & $17.31( \pm 10.03)$ & $20.75( \pm 10.91)$ & $15.97( \pm 8.69)$ & $10.74( \pm 5.45)$ \\
\hline \multicolumn{2}{|c|}{$\begin{array}{l}\text { Number of depressive episodes after } 24 \text { months } \\
\text { of treatment }\end{array}$} & $0.99( \pm 1.45)$ & $0.61( \pm 0.90)$ & $1.37( \pm 2.06)$ & $1.26( \pm 0.87)$ \\
\hline \multicolumn{2}{|c|}{$\begin{array}{l}\text { Number of manic/hypomanic episodes after } \\
24 \text { months of treatment }\end{array}$} & $0.41( \pm 1.33)$ & $0.27( \pm 0.72)$ & $0.68( \pm 2.06)$ & $0.21( \pm 0.42)$ \\
\hline \multicolumn{2}{|c|}{$\begin{array}{l}\text { Number of mixed episodes after } 24 \text { months } \\
\text { of treatment }\end{array}$} & $0.29( \pm 0.66)$ & $0.29( \pm 0.73)$ & $0.37( \pm 0.68)$ & $0.11( \pm 0.32)$ \\
\hline
\end{tabular}

Notes: Standard deviations and percentages are sorted into brackets and refer to single group.

Statistics: ${ }^{\circ} \chi^{2}=28.28, \mathrm{df}=16, \mathrm{p}=0.022 ; \infty \chi^{2}=34.74, \mathrm{df}=14, \mathrm{p}=0.001 ;{ }^{*} \mathrm{~F}=26.70, \mathrm{p}<0.0001 ; * * \mathrm{~F}=102.10, \mathrm{p}<0.0001 ;{ }^{\circ} \mathrm{F}=3.59, \mathrm{p}=0.03 ; \square \mathrm{F}=8.43, \mathrm{p}<0.0001$; $\square \square \mathrm{F}=3.57, \mathrm{p}=0.03$.

No differences were found among the three subgroups with regard to mood stabilizer response in terms of prevention of manic/hypomanic $(\mathrm{F}=1.29 ; \mathrm{p}=0.28)$ and mixed episodes $(\mathrm{F}=1.02 ; \mathrm{p}=0.363)$.

\section{Discussion}

Demographic and clinical features of study sample are consistent with literature data, given a higher prevalence of early-onset subjects ${ }^{13}$ and a significant rate of rapid-cycling patients, approximately the $15 \%$ of the sample. ${ }^{27}$ It is noteworthy to highlight a DUI of approximately 10 years in the study sample which is consistent with published data in the field. ${ }^{6}$ In addition, as in many other studies with bipolar patients, a frequent family history of affective disorder $\mathrm{s}^{28}$ and a frequent comorbidity with panic disorder and substance abuse $^{6,29}$ were found within the study sample. 
With respect to clinical differences among the three subgroups divided on the basis of the AAO, early-onset patients showed more frequently comorbid substance abuse and obsessive compulsive disorder, factors that have been associated with poor prognosis. ${ }^{30,31}$

The main finding of the present study is that mood stabilizer treatment seemed to be more effective in preventing depressive episodes in early-onset bipolar patients compared to middle- and late-onset subjects. This aspect, along with a longer DUI in this subgroup of patients, underscores the importance of early diagnosis and treatment in relation to prognosis and treatment response in these patients. In fact, it may be speculated that early-onset bipolar subjects, even though characterized by more severe clinical features (eg, more frequent comorbidity with substance abuse), delayed treatment-seeking, ${ }^{14}$ and longer DUI, may nonetheless show a favorable response to mood stabilizers once these compounds are initiated compared to late-onset patients. On the other hand, with regard to the prevention of manic/hypomanic recurrences, mood stabilizers were equally effective across the three subgroups of patients.

Another original indication from the present study in terms of long-term response to mood stabilizers according to different ages at onset is that middle-onset subjects were more similar to late-onset ones, supporting the hypothesis that early- and middle-/late-onset BDs might be considered distinct subtypes. Of note, a recent epidemiological study concluded that AAO reflects underlying genetic heterogeneity in BD and, thus, AAO might conceivably be used to identify more homogeneous groups of families with $\mathrm{BD}$, and thereby facilitate the mapping of illness susceptibility genes. ${ }^{32}$ Genetic investigation would support this hypothesis and a recent study showed that the polymorphism Val66Met for the gene of brain-derived neurotrophic factor (BDNF) would be specifically associated with early AAO in patients with BD. ${ }^{33}$

Further studies with larger samples and longer follow-up observation are warranted to confirm present findings which are limited by the relatively small sample size and the open design. In addition, it should be taken into account that differences in treatment-response across different subgroups of bipolar patients may have been influenced by the different types of mood stabilizers used given that long-term monotherapies such as lithium, anticonvulsants, or atypical antipsychotics may have different impact according to patients' clinical profile. ${ }^{34}$ In this perspective, in fact, significant differences regarding the type of mood stabilizer prescribed across the three subgroups, with a prevalence of atypical antipsychotics in the late-onset subgroup and lithium/valproate in the early-onset subgroup, were found. The more frequent use of atypical antipsychotics in the late-onset subgroup may be read in light of a more favorable pharmacodynamic profile and tolerability for these agents compared to classical mood stabilizers. ${ }^{35}$ On the other hand, lithium was the most frequently used mood stabilizer in the early-onset subgroup, as reported in another retrospective study involving 139 early-onset bipolar subjects. ${ }^{36} \mathrm{~A}$ potential explanation of this finding may be that clinicians would prescribe lithium for early-onset patients in light of a possible better tolerability and greater efficacy of this compound in the first phases of $\mathrm{BD},{ }^{37}$ even though this hypothesis has been questioned in recent studies. ${ }^{38,39}$ Finally, even though the collection of AAO was established with the SCID by trained psychiatrists and always controlled with additional fonts, the possibility of recall bias, particularly for older patients, cannot be completely ruled out.

\section{Disclosure}

Prof. Altamura, Drs Dell'Osso, Buoli, Riundi, D’Urso, Pozzoli, Bassetti, and Mundo do not have any affiliation or financial interest in any organization that might imply a conflict of interest with the present article.

\section{References}

1. Kessler RC, Merikangas KR, Wang PS. Prevalence, comorbidity, and service utilization for mood disorders in the United States at the beginning of the twenty-first century. Annu Rev Clin Psychol. 2007;3:137-158.

2. Merikangas KR, Akiskal HS, Angst J, et al. Lifetime and 12-month prevalence of bipolar spectrum disorder in the National Comorbidity Survey replication. Arch Gen Psychiatry. 2007;64:543-552.

3. Suppes T, Brown E, Schuh LM, et al. Rapid versus non-rapid cycling as a predictor of response to olanzapine and divalproex sodium for bipolar mania and maintenance of remission: post hoc analyses of 47-week data. J Affect Disord. 2005;89:69-77.

4. Antai-Otong D. Treatment considerations for patients experiencing rapid-cycling BD. Perspect Psychiatr Care. 2006;42:55-58.

5. Schneck CD. Treatment of rapid-cycling BD. J Clin Psychiatry. 2006;67:22-27.

6. Goldberg JF, Ernst CL. Features associated with the delayed initiation of mood stabilizers at illness onset in bipolar disorder. J Clin Psychiatry. 2002;63:985-991

7. Altamura AC, Dell'Osso B, Albano A, et al. Duration of untreated illness in mood and anxiety disorders. Int $J$ Neuropsychopharmacol. 2008;11(S1):201-202.

8. Baldessarini RJ, Tondo L, Hennen J, Floris G. Latency and episodes before treatment: response to lithium maintenance in bipolar I and II disorders. Bipolar Disord. 1999;1(2):91-97.

9. Baethge C, Smolka MN, Gruschka P, et al. Does prophylaxis-delay in BD influence outcome? Results from a long-term study of 147 patients. Acta Psychiatr Scand. 2003;107:260-267.

10. Baethge C, Tondo L, Bratti IM, et al. Prophylaxis latency and outcome in BDs. Can J Psychiatry. 2003;48:449-457.

11. Arnold LM. Gender differences in BD. Psychiatr Clin North Am. 2003;26:595-620. 
12. Hendrick V, Altshuler LL, Gitlin MJ, et al. Gender and bipolar illness. J Clin Psychiatry. 2000;61:393-396.

13. Kawa I, Carter JD, Joyce PR, et al. Gender differences in BD: age of onset, course, comorbidity, and symptom presentation. Bipolar Disord. 2005; 7:119-125.

14. Suominen K, Mantere O, Valtonen H, et al. Early age at onset of bipolar disorder is associated with more severe clinical features but delayed treatment seeking. Bipolar Disord. 2007;9:698-705.

15. Perlis RH, Myahara S, Marangell LB, et al; STEP-BD Investigators. Long-term implications of early onset in bipolar disorder: data from the first 1000 participants in the systematic treatment enhancement program for bipolar disorder. Biol Psychiatry. 2004;55:875-881.

16. Zanetti MV, Cordeiro Q, Busatto GF. Late onset bipolar disorder associated with white matter hyperintensities: a pathophysiological hypothesis. Progr Neuropsychopharmacol Biolog Psychiatry. 2007;31:551-556.

17. Tsai SY, Lee HC, Chen CC, et al. Cognitive impairment in later life in patients with early-onset bipolar disorder. Bipolar Disord. 2007;9:868-875.

18. Lehmann SW, Rabins PV. Factors related to hospitalization in elderly manic patients with early and late-onset bipolar disorder. Int J Geriatr Psychiatry. 2006;21:1060-1064.

19. Leboyer M, Henry C, Paillere-Martinot ML, Bellivier F. Age at onset in bipolar affective disorders: a review. Bipolar Disord. 2005;7:111-118.

20. Bellivier F, Golmard JL, Rietschel M, et al. Admixture analysis of age at onset in bipolar I affective disorder. Arch Gen Psychiatry. 2001;58(5):510-512.

21. Bellivier F, Golmard JL, Rietschel M, et al. Age at onset in bipolar I affective disorder: further evidence for three subgroups. Am J Psychiatry. 2003;160:999-1001.

22. American Psychiatric Association. Diagnostic and Statistical Manual of Mental Disorders, 4th edition, Text Revision. Washington DC: American Psychiatric Association; 2000.

23. First MB, Spitzer RL, Gibbon M, et al. Structured Clinical Interview for DSM-IV-TR Axis I Disorders, Research Version, Patient Edition. (SCID-I/P) New York, NY: Biometrics Research, New York State Psychiatric Institute; 2002.

24. American Psychiatric Association. Practice Guidelines for the Treatment of Psychiatric Disorders. Arlington VA: American Psychiatric Association; 2006.
25. Hamilton M. A rating scale for depression. J Neurol Neurosurg Psychiatry. 1960;23:56-62.

26. Young RC, Biggs JT, Ziegler VE, et al. A rating scale for Mania: reliability, validity and sensitivity. Br J Psychiatry. 1978;133:429-435.

27. Dubovsky SL. Rapid cycling bipolar disease: new concepts and treatments. Curr Psychiatr Rep. 2001;3:451-462.

28. Taylor L, Faraone SV, Tsuang MT. Family, twin, and adoption studies of bipolar disease. Curr Psychiatry Rep. 2002;4:130-133.

29. Goodwin RD, Hoven CW. Bipolar-panic comorbidity in the general population: prevalence and associated morbidity. J Affect Disord. 2002;70:27-33.

30. Masi G, Perugi G, Toni C, et al. Obsessive-compulsive bipolar comorbidity: focus on children and adolescent. J Affect Disord. 2004; 78:175-183.

31. Brown ES. Bipolar disorder and substance abuse. Psychiatr Clin North Am. 2005;28:415-425.

32. Lin PI, McInnis MG, Potash JB, et al. Clinical correlates and familial aggregation of age at onset in bipolar disorder. Am J Psychiatry. 2006; 163:240-246.

33. Tang J, Xiao L, Shu C, et al. Association of the brain-derived neurotrophic factor gene and bipolar disorder with early age of onset in mainland China. Neurosci Lett. 2008;433:98-102.

34. Grof P. Selecting effective long-term treatment for bipolar patients: monotherapy and combinations. J Clin Psychiatry. 2003;64(Suppl 5):53-61.

35. Sajatovic M, Madhusoodanan S, Coconcea N. Managing bipolar disorder in the elderly: defining the role of the newer agents. Drugs Aging. 2005;22:39-54.

36. Rajeev J, Srinath S, Girimaji S, et al. A systematic chart review of the naturalistic course and treatment of early-onset bipolar disorder in a child and adolescent psychiatry center. Compr Psychiatry. 2004; 45:148-154.

37. Maj M, Pirozzi R, Magliano L. Late non-response to lithium prophylaxis in bipolar patients: prevalence and predictors. J Affect Disord. 1996;39:39-42.

38. Kleindienst N, Engel R, Greil W. Which clinical factors predict response to prophylactic lithium? A systematic review for bipolar disorders. Bipolar Disord. 2005;7:404-417.

39. Rohayem J, Baylé JF, Richa S. [Predictors of prophylactic response to lithium]. Encephale. 2008;34(4):394-399.
Neuropsychiatric Disease and Treatment

\section{Publish your work in this journal}

Neuropsychiatric Disease and Treatment is an international, peerreviewed journal of clinical therapeutics and pharmacology focusing on concise rapid reporting of clinical or pre-clinical studies on a range of neuropsychiatric and neurological disorders. This journal is indexed on PubMed Central, the 'PsycINFO' database and CAS, and is the official

\section{Dovepress}

journal of The International Neuropsychiatric Association (INA). The manuscript management system is completely online and includes a very quick and fair peer-review system, which is all easy to use. Visit http://www.dovepress.com/testimonials.php to read real quotes from published authors. 